\title{
Associations between oxygen delivery and cardiac index with hyperlactatemia during cardiopulmonary bypass
}

Ignazio Condello, PhD, ${ }^{\text {a }}$ Giuseppe Santarpino, MD, ${ }^{\text {bc,d }}$ Giuseppe Nasso, MD, ${ }^{a}$ Marco Moscarelli, MD, ${ }^{a}$ Flavio Fiore, MD, ${ }^{a}$ and Giuseppe Speziale, $\mathrm{MD}^{\mathrm{a}}$

\section{ABSTRACT}

Objective: Metabolism management plays an essential role during cardiopulmonary bypass (CPB). There are different metabolic management devices integrated to heart-lung machines; the most commonly used and accepted metabolic target is indexed oxygen delivery $\left(\mathrm{DO}_{2 \mathrm{i}}\right)\left(280 \mathrm{~mL} / \mathrm{min} / \mathrm{m}^{2}\right)$ and cardiac index $(\mathrm{Cl})(2.4 \mathrm{~L} / \mathrm{min} /$ $\mathrm{m}^{2}$ ), which can be managed independently or according to other metabolic parameters. Our objective was to compare lactate production during CPB procedures using different metabolic management: $\mathrm{DO}_{2 i}$ in relation to indexed oxygen extraction ratio $\left(\mathrm{O}_{2} E \mathrm{ER}_{\mathrm{i}}\right)$ and $\mathrm{Cl}$ in relation to mixed venous oxygen saturation $\left(\mathrm{SVO}_{2}\right)$.

Methods: Data on 500 CPB procedures were retrospectively collected in a specialized regional tertiary cardiac surgery center in Italy between September and 2012 and November 2019. In group $A$, the $\mathrm{DO}_{2 \mathrm{i}}$ with $280 \mathrm{~mL} / \mathrm{min} / \mathrm{m}^{2}$ target in relation to $\mathrm{O}_{2} \mathrm{ER}_{\mathrm{i}} 25 \%$ was used; in group $\mathrm{B}, \mathrm{Cl}$ with $2.4 \mathrm{~L} / \mathrm{min} / \mathrm{m}^{2}$ target in relation to $\mathrm{SvO}_{2} 75 \%$ was used. During CPB, serial arterial blood gas analyses with blood lactate and glucose determinations were obtained. Hyperlactatemia (HL) was defined as a peak arterial blood lactate concentration $>3 \mathrm{mmol} / \mathrm{L}$. The postoperative outcome of patients with or without $\mathrm{HL}$ was compared.

Results: Eight pre- and intraoperative factors were found to be significantly associated with peak blood lactate level during CPB at univariate analysis. $\mathrm{HL}(>3 \mathrm{mmol} /$ $L)$ was detected in $15(6 \%)$ patients of group $A$ and in $42(16.8 \%)$ patients of group $\mathrm{B}(P=.022)$; hyperglycemia $(>160 \mathrm{mg} / \mathrm{dL})$ was found in $23(9.2 \%)$ patients of group $A$ and in $53(21.2 \%)$ patients of group $B(P=.038)$. Patients with HL during CPB had a significant increase in serum creatinine value, higher rate of prolonged mechanical ventilation time and intensive care unit stay. A cutoff of $\mathrm{DO}_{2 i}<270 \mathrm{~mL} / \mathrm{min} / \mathrm{m}^{2}$ in relation to $\mathrm{O}_{2} \mathrm{ER}_{\mathrm{i}}>35 \%$ in group $\mathrm{A}$ and a cutoff of $\mathrm{Cl}<2.4 \mathrm{~L} / \mathrm{min} / \mathrm{m}^{2}$ in relation to $\mathrm{SvO}_{2}<65 \%$ in group $\mathrm{B}$ were found to have a positive predictive value of $80 \%$ and $75 \%$ for $\mathrm{HL}$, respectively. A cutoff of $\mathrm{DO}_{2 i}>290 \mathrm{~mL} / \mathrm{min} / \mathrm{m}^{2}$ in relation to $\mathrm{O}_{2} \mathrm{ER}_{\mathrm{i}} 24 \%$ in group $\mathrm{A}$ and a cutoff of $\mathrm{Cl}>2.4 \mathrm{~L} / \mathrm{min} / \mathrm{m}^{2}$ in relation to $\mathrm{SvO}_{2}$ $>75 \%$ in group $\mathrm{B}$ were found to have a negative predictive value of $78 \%$ and $62 \%$ for HL, respectively.

Conclusions: This retrospective observational analysis showed that management of $\mathrm{DO}_{2 \mathrm{i}}$ in relation to $\mathrm{O}_{2} \mathrm{ER}_{\mathrm{i}}$ was $16 \%$ more specific in terms of negative predictive value for $\mathrm{HL}$ during $\mathrm{CPB}$ compared with the use of $\mathrm{Cl}$ in relation to $\mathrm{SvO}_{2}$. Group $\mathrm{A}$ reported a significant reduction in the incidence of intraoperative lactate peak, correlated with postoperative reduction of serum creatinine value, mechanical ventilation time, and intensive care unit stay, compared with group B. (JTCVS Techniques 2020;2:92-9)

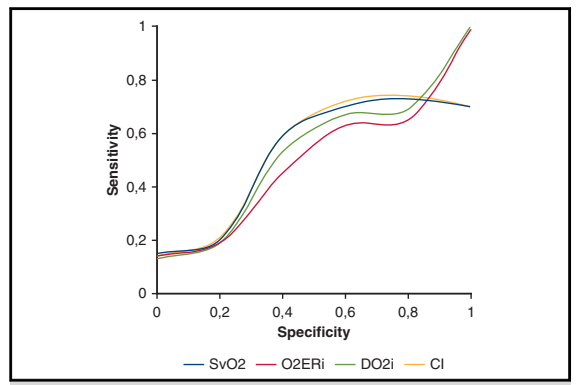

Sensitivity/specificity curves for cardiac index, indexed oxygen delivery, indexed oxygen extraction ratio, and mixed venous oxygen saturation.

\section{CENTRAL MESSAGE}

This study showed that management of indexed oxygen delivery in relation to indexed oxygen extraction ratio was more specific in terms of negative predictive value for hyperlactatemia during cardiopulmonary bypass compared with cardiac index and mixed venous oxygen saturation.

\section{PERSPECTIVE}

The management of indexed oxygen delivery in relation to indexed oxygen extraction ratio follow the cardiopulmonary bypass was more specific in terms of negative predictive value for hyperlactatemia compared to the use of cardiac index in relation to mixed venous oxygen saturation. That management can correlate with postoperative better outcome especially in terms of serum creatinine, mechanical ventilation time, and intensive care unit stay

See Commentaries on pages 100 and 102.
From the a Department of Cardiac Surgery, Anthea Hospital, GVM Care \& Research, Bari, Italy; ${ }^{b}$ Department of Cardiac Surgery, Città di Lecce Hospital, GVM Care \& Research, Lecce, Italy; ${ }^{\circ}$ Department of Cardiac Surgery, Paracelsus Medical University, Nuremberg, Germany; and ${ }^{\mathrm{d} C}$ Cardiac Surgery Unit, Department of Experimental and Clinical Medicine-University "Magna Graecia," Catanzaro, Italy.

Received for publication Feb 20, 2020; revisions received Feb 20, 2020; accepted for publication April 2, 2020; available ahead of print April 13, 2020
Address for reprints: Ignazio Condello, PhD, Anthea Hospital, GVM Care \& Research, Via Camillo Rosalba 35/37, 70124 Bari, Italy (E-mail: ignicondello@ hotmail.it).

2666-2507

Copyright (C) 2020 The Authors. Published by Elsevier Inc. on behalf of The American Association for Thoracic Surgery. This is an open access article under the CC BY-NCND license (http://creativecommons.org/licenses/by-nc-nd/4.0/).

https://doi.org/10.1016/j.xjtc.2020.04.001 

Abbreviations and Acronyms
$\mathrm{CI}=$ cardiac index
$\mathrm{CPB}=$ cardiopulmonary bypass
$\mathrm{DO}_{2 \mathrm{i}}=$ indexed oxygen delivery
$\mathrm{Hb}=$ hemoglobin
Hct = hematocrit
$\mathrm{HL}=$ hyperlactatemia
ICU = intensive care unit
$\mathrm{O}_{2} \mathrm{ER}_{\mathrm{i}}=$ indexed oxygen extraction ratio
$\mathrm{SvO}_{2}=$ venous oxygen saturation

Video clip is available online.

During cardiac surgery with cardiopulmonary bypass (CPB) in adult patients, hyperlactatemia (HL) is detectable at a considerable rate $(10 \%-20 \%)^{1,2}$ and is associated with postoperative morbidity and mortality. ${ }^{1}$ At present, the nature of HL during and after cardiac operations is not totally clear, but the majority of authors ${ }^{3-6}$ tend to attribute this finding to tissue hypoxia (type A HL) even if type B HL (without tissue hypoxia) has been advocated in some cases. ${ }^{7-9}$ The main factors leading to a possible organ dysoxia during $\mathrm{CPB}$ are the hemodilution degree ${ }^{10}$ and a low peripheral oxygen delivery. ${ }^{1,2,4-6,10-12}$ In the state of perfusion, there are different metabolic management devices integrated to the heart-lung machine (eg, Quantum Spectrum [Spectrum Medical, Cheltenham, England], Connect Livanova [London, England], CDI Terumo Medical, Vaughan, Ontario, Canada], Landing Eurosets [Medolla, Italy]), with multiple measured and calculated parameters; the most commonly used and accepted metabolic target for the scientific community is the value of indexed oxygen delivery $\left(\mathrm{DO}_{2 \mathrm{i}}\right)(280 \mathrm{~mL} /$ $\left.\mathrm{min} / \mathrm{m}^{2}\right)$ and the cardiac index $(\mathrm{CI})\left(2.4 \mathrm{~L} / \mathrm{min} / \mathrm{m}^{2}\right)$. These parameters can be managed independently or according to other metabolic parameters (eg, hemoglobin [Hb], vascular resistance, temperature, and diuresis), resulting in wide variability in CPB management of each center.

This study has the objective to compare lactate production during $\mathrm{CPB}$ procedures using different metabolic management: $\mathrm{DO}_{2 \mathrm{i}}$ in relation to indexed oxygen extraction ratio $\left(\mathrm{O}_{2} \mathrm{ER}_{\mathrm{i}}\right)$ (group $\mathrm{A}$ ), and $\mathrm{CI}$ in relation to mixed venous oxygen saturation $\left(\mathrm{SvO}_{2}\right)$ (group B) (Video 1).

\section{MATERIALS AND METHODS Population and Study Design}

This study presents a comparative retrospective analysis that has been carried out between 2 historical times: the first historical period (20122015) used conventional extracorporeal circulation with blood gas test for metabolic management during $\mathrm{CPB}$; the second historical period

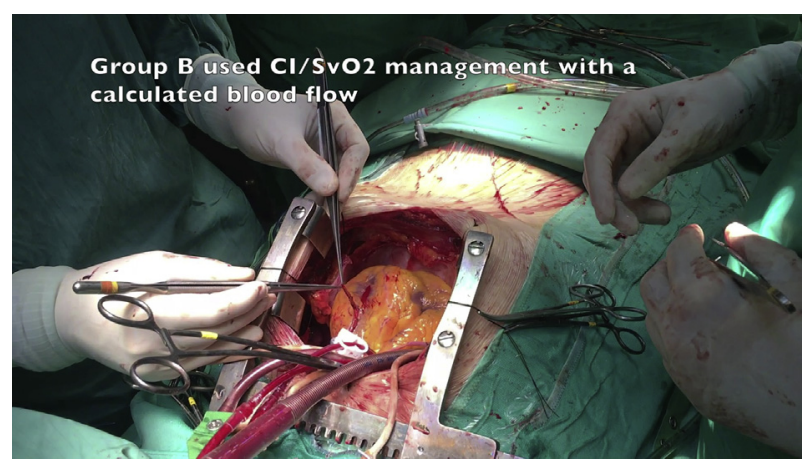

VIDEO 1. Ignazio Condello, $\mathrm{PhD}$, summarizes the results of the study and explains the relevance of the research for the readers of the Journal. Video available at: https://www.jtcvs.org/article/S2666-2507(20)30189-9/ fulltext.

(2016-2019) used conventional extracorporeal circulation with blood gas test and the integration with metabolic parameter monitoring system. Between September 2012 and November 2019, 500 adults aged $>28$ to 80 years were collected for elective cardiac surgery procedures, without chronic kidney failure and with calculated European System for Cardiac Operative Risk Evaluation II score (mean value, 4.1\%-4.5\%) at our institution (Department of Cardiothoracic Surgery, Anthea Hospital, Bari, Italy). The study protocol was approved by the local ethics committee and all patients provided written consent to scientific treatment of their data. Patients were divided into 2 groups for $\mathrm{CPB}$ metabolic management: in group $\mathrm{A}$ (study group, $\mathrm{n}=250$ ), the $\mathrm{DO}_{2 \mathrm{i}}$ target with a target of $280 \mathrm{~mL}$ / $\mathrm{min} / \mathrm{m}^{2}$ was used in relation to $\mathrm{O}_{2} \mathrm{ER}_{\mathrm{i}}$; in group $\mathrm{B}$ (control group, $\mathrm{n}=250$ ), the CI target with a target of $2.4 \mathrm{~L} / \mathrm{min} / \mathrm{m}^{2}$ was used in relation to $\mathrm{SvO}_{2}$.

\section{Data Collection}

Patients were selected according to the following criteria:

- Elective, primary cardiac surgery: complete $\mathrm{CPB}$ and cardioplegic arrest had to be foreseen with an expected CPB duration $>90$ minutes.

- Patients were excluded if they presented abnormal plasma lactate levels ( $>2 \mathrm{mmol} / \mathrm{L}$ ) before entering $\mathrm{CPB}$, renal or liver failure, obesity, uncompensated diabetes, autoimmune disease, active infection, any immunosuppressant therapy, or coagulation disorder. Patients undergoing surgery with circulatory arrest or having preoperative hematocrit (Hct) $<27 \%$ were also excluded.

The cardiac surgery procedures that were analyzed for this study are coronary artery bypass graft $(n=200)$, isolated aortic valve replacement $(\mathrm{n}=100)$ and mitral valve repair with minimally invasive approach $(\mathrm{n}=200)$

Preoperative data included patient demographic characteristics, baseline serum creatinine levels, ventricular ejection fraction, comorbidities (eg, chronic obstructive pulmonary disease or previous cerebrovascular accident), baseline Hb, logistic European System for Cardiac Operative Risk Evaluation II score and New York Heart Association functional class. ${ }^{2}$

Perioperative data included type of operation, $\mathrm{CPB}$ duration, nadir body temperature during $\mathrm{CPB}$, nadir $\mathrm{Hct}$ and $\mathrm{Hb}$ values (measured at the start of the $\mathrm{CPB}$ operation and every 20 minutes thereafter), nadir $\mathrm{DO}_{2 \mathrm{i}}$, nadir $\mathrm{DO}_{2 \mathrm{i}} / \mathrm{O}_{2} \mathrm{ER}_{\mathrm{i}}$ ratio during $\mathrm{CPB}$, nadir $\mathrm{CI}$, nadir $\mathrm{CI} / \mathrm{SvO}_{2}$, peak serum lactate, and glucose during CPB. Postoperative data included peak serum creatinine, mechanical ventilation time, and days spent in the intensive care unit (ICU).

The primary end points were specificity and sensitivity, positive and negative predictive value for $\mathrm{HL}$ between target $\mathrm{DO}_{2 \mathrm{i}}$ in relation to $\mathrm{O}_{2} \mathrm{ER}_{\mathrm{i}}$ during $\mathrm{CPB}$ compared with the control group in terms of 
TABLE 1. Preoperative profile and operative data

\begin{tabular}{lcc}
\hline \multicolumn{1}{c}{ Characteristic } & $\begin{array}{c}\text { Group A } \\
(\mathbf{n = 2 5 0 )}\end{array}$ & $\begin{array}{c}\text { Group B } \\
(\mathbf{n = 2 5 0})\end{array}$ \\
\hline Mean age (y) & 69.6 & 71.3 \\
\hline Male sex & $110(44)$ & $121(48)$ \\
\hline Mean body surface area $\left(\mathrm{m}^{2}\right)$ & 1.75 & 1.79 \\
\hline Mean left ventricular ejection fraction (\%) & 46 & 48 \\
\hline Median NYHA functional class & 2 & 2 \\
\hline EuroSCORE II (mean) & 4.1 & 4.7 \\
\hline Pre-CPB hematocrit (\%) & $32.4 \pm 1.2$ & $32.6 \pm 1.9$ \\
\hline Pre-CPB Hb (g/dL) & $10.4 \pm 1.1$ & $10.8 \pm 1.2$ \\
\hline No. of chronic obstructive pulmonary & 23 & 24 \\
disease cases (mean) & & \\
\hline Creatinine (mg/dL) & $1.09 \pm 0.6$ & $1.06 \pm 0.9$ \\
\hline Obstructive coronary artery disease (\%) & 23 & 24 \\
\hline Var & 23 & \\
\hline
\end{tabular}

Values are presented as $\mathrm{n}(\%)$, or mean \pm standard deviation. NYHA, New York Heart Association; EuroSCORE, European System for Cardiac Operative Risk Evaluation; $C P B$, cardiopulmonary bypass; $H b$, hemoglobin.

intraoperative lactate and glycemia trends. Secondary end points were peak postoperative serum creatinine level, ${ }^{13,14}$ mechanical ventilation time, and length of ICU stay.

\section{Anesthetics and Surgical Procedures}

Patients were monitored with 5-lead electrocardiography, a left radial artery catheter, capnography, pulse oximetry, and rectal/urine bladder temperature sensors. Transesophageal echocardiography was performed in all patients. Anticoagulant therapy consisted of heparin sodium before $\mathrm{CPB}$ at $300 \mathrm{IU} / \mathrm{kg}$ to give an activated clotting time of $>480$ seconds (ACT PLUS; Medtronic, Minneapolis, Minn); for antagonization of heparin, 0.5 to $0.75 \mathrm{mg}$ protamine was applied for every $100 \mathrm{U}$ heparin. Anesthesia was induced with intravenous sufentanil $(0.5-1 \mu \mathrm{g} / \mathrm{kg})$ and midazolam (0.08$0.2 \mathrm{mg} / \mathrm{kg}$ ), and tracheal intubation was facilitated with intravenous rocuronium $(0.6-1 \mathrm{mg} / \mathrm{kg})$. Anesthesia was maintained with propofol $(2-5 \mathrm{mg} / \mathrm{kg})$ and sufentanil $(0.5-2.0 \mu \mathrm{g} / \mathrm{kg})$, and the depth of anesthesia was monitored using bispectral index values (BIS XP; Aspect Medical System, Newton, Mass). The dose of propofol was titrated to maintain bispectral index values between 40 and 60 . Aortic valve replacement and coronary artery bypass graft procedures were performed in median sternotomy with central cannulation, MVR in right minithoracotomy approach with peripheral cannulation, and surgical procedures were performed as routine by 2 surgeons. Concentrated red blood cells were transfused whenever $\mathrm{Hb}$ concentrations fell below $6 \mathrm{~g} / \mathrm{dL}$ during surgery or below $8 \mathrm{~g} / \mathrm{dL}$ during ICU stay.

\section{CPB Setting}

Both open (Admiral; Remo-well Eurosets; EOS Dideco; Mirandola, Italy; Inspire 6F; LivaNova) and closed circuits (Closed Eurosets) were used for CPB. Pericardial blood was collected separately and could be processed or reinjected, if needed. The hard shell and soft shell reservoir, oxygenating module and circuits were treated with phosphorylcholine (Agile Eurosets; P.hisio. LivaNova). All patients were treated with mild hypothermic CPB $\left(34^{\circ} \mathrm{C}-36^{\circ} \mathrm{C}\right)$; a volume of $1250 \mathrm{~mL}$ crystalloid Ringer acetate solution was used for priming. The surgical procedures selected for this study do not justify the use of moderate hypothermia by falling below $34^{\circ} \mathrm{C}$. For this reason, in the event of an initial increase in anaerobic metabolism, the first compensation approach was not to lower the temperature but possibly liquids or red blood cells were integrated.

The hardware consisted of a Stöckert S5 heart-lung machine and a Stöckert Heater Cooler System 3T (LivaNova) and the same cannulae were employed in both groups. For the administration of myocardial protection, a closed circuit for cardioplegia with heat exchanger, with an infusion syringe pump in series and Saint Thomas solution with procaine were used and repeated every 30 minutes. Group A used the Landing monitoring system (Eurosets) for $\mathrm{DO}_{2}$ management during CPB. In both groups, blood gas analyses were performed using alpha-stat management with a blood-gas analyzer (GEM Premier 3000 IQM; Instrumentation Laboratory, Werfen Group IVD company, Munich, Germany) set to measure at $37^{\circ} \mathrm{C} .{ }^{4}$ On the basis of arterial blood data, we assessed the lowest Hct (percentage) on CPB; every 20 minutes, an arterial blood gas analysis, including blood glucose and lactate determination, was obtained. An $\mathrm{Hb}$ value $<6$ to $7 \mathrm{~g} / \mathrm{dL}$ during $\mathrm{CPB}$ was considered the trigger point for red blood cell transfusion. All patients received tranexamic acid according to the routine protocol. Mean arterial pressure during CPB procedures was managed for values between 55 and $70 \mathrm{~mm} \mathrm{Hg}$.

\section{Metabolic Management During CPB in Group A}

In group $\mathrm{A}, \mathrm{DO}_{2 \mathrm{i}}$ with a target of $280 \mathrm{~mL} / \mathrm{min} / \mathrm{m}^{2}$ was managed in relation to $\mathrm{O}_{2} \mathrm{ER}_{\mathrm{i}}$ (the cutoff for increase in $\mathrm{DO}_{2 \mathrm{i}}$ was $>25 \% \mathrm{O}_{2} \mathrm{ER}_{\mathrm{i}}$, the cutoff for decrease in $\mathrm{DO}_{2 \mathrm{i}}$ was $<25 \% \mathrm{O}_{2} \mathrm{ER}_{\mathrm{i}}$ ). $\mathrm{DO}_{2 \mathrm{i}}$ and $\mathrm{O}_{2} \mathrm{ER}_{\mathrm{i}}$-related measurements were performed using a Landing system provided by Eurosets. Data were collected every 5 seconds during CPB. Data required to calculate

TABLE 2. Operative data

\begin{tabular}{|c|c|c|c|}
\hline Parameter & $\begin{array}{c}\text { Group A } \\
(\mathbf{n}=\mathbf{2 5 0})\end{array}$ & $\begin{array}{l}\text { Group B } \\
(\mathbf{n}=\mathbf{2 5 0})\end{array}$ & $P$ value \\
\hline CPB time (min) & $125 \pm 13.2$ & $120 \pm 8.37$ & .92 \\
\hline Aortic crossclamp time (min) & $61 \pm 4$ & $68 \pm 7$ & .75 \\
\hline Nadir temperature $\left({ }^{\circ} \mathrm{C}\right)$ during $\mathrm{CPB}$ & $34.9 \pm 1.1$ & $34.7 \pm 2.1$ & .75 \\
\hline Nadir hemoglobin value $(\mathrm{mg} / \mathrm{dL})$ during CPB & $8.73 \pm 1.53$ & $8.89 \pm 1.25$ & .88 \\
\hline Nadir hematocrit (\%) during CPB & $25.6 \pm 3.8$ & $25.9 \pm 3.1$ & .89 \\
\hline Nadir $\mathrm{DO}_{2 \mathrm{i}}\left(\mathrm{mL} / \mathrm{min} / \mathrm{m}^{2}\right)$ during CPB & $290 \pm 29$ & $278 \pm 14$ & .039 \\
\hline $\mathrm{O}_{2} \mathrm{ER}_{\mathrm{i}}(\%)$ during $\mathrm{CPB}$ & $24 \pm 1$ & $29 \pm 5$ & .0029 \\
\hline Nadir CI $\left(\mathrm{L} / \mathrm{min} / \mathrm{m}^{2}\right)$ during CPB & $2.6 \pm 0.2$ & $2.4 \pm 0.1$ & .0032 \\
\hline Nadir $\mathrm{SvO}_{2}(\%)$ & $81 \pm 2$ & $70 \pm 5$ & .0029 \\
\hline
\end{tabular}

Values are presented as mean \pm standard deviation. $C P B$, Cardiopulmonary bypass; $D O_{2 i}$, indexed oxygen delivery; $O_{2} E R_{i}$, indexed oxygen extraction ratio; $C I$, cardiac index; $\mathrm{SvO}_{2}$, mixed venous oxygen saturation. 
TABLE 3. Univariate analysis (correlation matrix)

\begin{tabular}{lcc}
\hline \multicolumn{1}{c}{ Factor } & Correlation coefficient & $\boldsymbol{P}$ value \\
\hline Age $(\mathrm{y})$ & -0.079 & .029 \\
Isolated coronary operation & -0.075 & .039 \\
Lowest temperature on CPB & -0.219 & .001 \\
Lowest hematocrit on CPB & -0.149 & .001 \\
CPB duration & 0.049 & .001 \\
Lowest pump flow & -0.239 & .001 \\
CPB lowest $\mathrm{DO}_{2 \mathrm{i}}$ & -0.254 & .001 \\
CPB peak blood glucose & 0.497 & .001 \\
\hline
\end{tabular}

$C P B$, Cardiopulmonary bypass; $D O_{2 i}$, indexed oxygen delivery.

$\mathrm{DO}_{2 \mathrm{i}}$ and $\mathrm{O}_{2} \mathrm{ER}_{\mathrm{i}}$ were arterial $\mathrm{Hb}$; measured parameters included arterial saturation, $\mathrm{SvO}_{2}$, blood pump flow, $\mathrm{Hb}$, arterial and venous temperature, mean arterial pressure, body surface area, and CI.

$\mathrm{DO}_{2 \mathrm{i}}$ was calculated using the following equation:

$$
\mathrm{DO}_{2 \mathrm{i}}\left(\mathrm{mL} / \mathrm{min} / \mathrm{m}^{2}\right)=10 \times \text { pump flow }\left(\mathrm{L} / \mathrm{min} / \mathrm{m}^{2}\right) \times
$$

arterial $\mathrm{O}_{2}$ content $(\mathrm{mL} / 100 \mathrm{~mL})$,

where arterial $\mathrm{O}_{2}$ content was calculated as follows: $\left(\mathrm{CaO}_{2}\right)$ arterial $\mathrm{O}_{2}$ content $(\mathrm{mL} / 100 \mathrm{~mL})=\mathrm{Hb}(\mathrm{mg} / \mathrm{dL}) \times 1.34 \times \mathrm{Hb}$ saturation $(\%)+0.003 \times \mathrm{O}^{2}$ tension $(\mathrm{mm} \mathrm{Hg})$.

$\mathrm{O}_{2} \mathrm{ER}_{\mathrm{i}(\%)}$ was calculated using the following equation: ${ }^{2,15}$

$$
\mathrm{O}_{2} \mathrm{ER}_{\mathrm{i}}=\mathrm{VO}_{2 \mathrm{i}} / \mathrm{DO}_{2 \mathrm{i}}=\left(\mathrm{CaO}_{2}-\mathrm{CvO}_{2}\right) / \mathrm{CaO}_{2}
$$

\section{Metabolic Management During CPB in Group B}

In group $\mathrm{B}, \mathrm{CI}$ with a target of $2.4 \mathrm{~L} / \mathrm{min} / \mathrm{m}^{2}$ was managed in relation to $\mathrm{SvO}_{2}$ (the cutoff for increase in CI was $<75 \% \mathrm{SvO}_{2}$, the cutoff for decrease in $\mathrm{CI}$ was $>75 \% \mathrm{SvO}_{2}$ ). Related measurements were performed using a Flowmeter probe in arterial line to measure the real flow of the roller pump and the blood gas analyzer (GEM Premier 3000 IQM; Instrumentation Laboratory, Werfen Group IVD company) set to measure at $37^{\circ} \mathrm{C}^{4}$ for

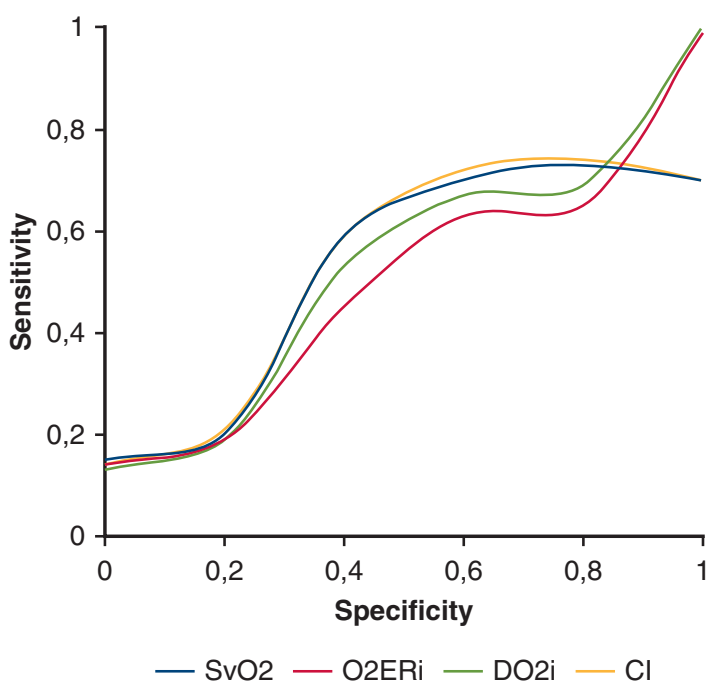

FIGURE 1. Receiver operating characteristic curves for lactate peak prediction based on target indexed oxygen delivery $\left(D O_{2 i}\right)$, indexed oxygen extraction ratio $\left(\mathrm{O}_{2} E R_{i}\right)$, cardiac index $(C I)$, and mixed venous oxygen saturation $\left(\mathrm{SvO}_{2}\right)$.
TABLE 4. Subgroup analysis for peak blood lactate and lowest indexed oxygen delivery $\left(\mathrm{DO}_{2 \mathrm{i}}\right)$ in relation to indexed oxygen extraction ratio $\left(\mathrm{O}_{2} \mathrm{ER}_{\mathrm{i}}\right)$ on cardiopulmonary bypass for group $\mathrm{A}$ $(\mathbf{n}=\mathbf{2 5 0})$

\begin{tabular}{lcccc}
\hline \multicolumn{1}{c}{ Variable } & $\begin{array}{c}\text { No } \mathbf{H L} \\
\text { or } \mathbf{H G}\end{array}$ & HL alone & HG alone & $\begin{array}{c}\text { HL and } \\
\text { HG }\end{array}$ \\
\hline No. of patients & 223 & 4 & 12 & 11 \\
\hline $\begin{array}{c}\text { Peak blood } \\
\text { lactate } \\
(\mathrm{mmol} / \mathrm{L})\end{array}$ & $1.28 \pm 0.45$ & $3.68 \pm 0.35$ & $1.82 \pm 0.65$ & $4.91 \pm 3.21$ \\
$\begin{array}{c}\text { Lowest } \mathrm{DO}_{2 \mathrm{i}} \\
\left(\mathrm{mL} / \mathrm{min}_{\mathrm{m}} \mathrm{m}^{2}\right)\end{array}$ & $304 \pm 21$ & $287 \pm 13$ & $289 \pm 21$ & $195 \pm 40$ \\
$\begin{array}{c}\mathrm{Highest} \\
\mathrm{O}_{2} \mathrm{ER}_{\mathrm{i}}(\%)\end{array}$ & $20 \pm 3$ & $25 \pm 2$ & $25 \pm 3$ & $38 \pm 4$ \\
\hline
\end{tabular}

Values are presented as mean \pm standard deviation. $H L$, Hyperlactatemia; $H G$, hyperglycemia; $D O_{2 i}$, indexed oxygen delivery; $\mathrm{O}_{2} E R_{i}$, indexed oxygen extraction ratio.

measurement of $\mathrm{SvO}_{2}$ during CPB. Data were collected every 20 minutes during $\mathrm{CPB}$

CI was calculated using the following formula:

$$
\mathrm{CI}\left(\mathrm{L} / \mathrm{min} / \mathrm{m}^{2}\right)=(\mathrm{Q}) \text { pump flow }(\mathrm{L} / \mathrm{min}) / \text { body surface area }\left(\mathrm{m}^{2}\right)
$$

where pump flow $(\mathrm{L} / \mathrm{min})=$ body surface area $\left(\mathrm{m}^{2}\right) \times \mathrm{CI}\left(\mathrm{L} / \mathrm{min} / \mathrm{m}^{2}\right)$.

$\mathrm{SvO}_{2}$, in the clinical and intensivist practice, was a true reflection of the global balance between oxygen delivery and consumption because it is measured through the venous drainage line during $\mathrm{CPB}$ where venous blood returning to the right heart from the superior vena cava, inferior vena cava, and the coronary sinus have mixed. $\mathrm{SvO}_{2}$ has been extensively studied and used clinically to monitor the global balance between $\mathrm{DO}_{2}$ and oxygen consumption. In the literature, for patients with multiple injuries, normal $\mathrm{SvO}_{2}$ values between $65 \%$ and $70 \%$ and increasing $\mathrm{DO}_{2}$ are more relevant for survival.

\section{Statistical Analysis}

All data are expressed as mean \pm standard error of the mean or as absolute numbers and percentage, as appropriate. Statistical analysis was performed using SPSS version 11.0 software (SPSS Inc, Chicago, Ill).

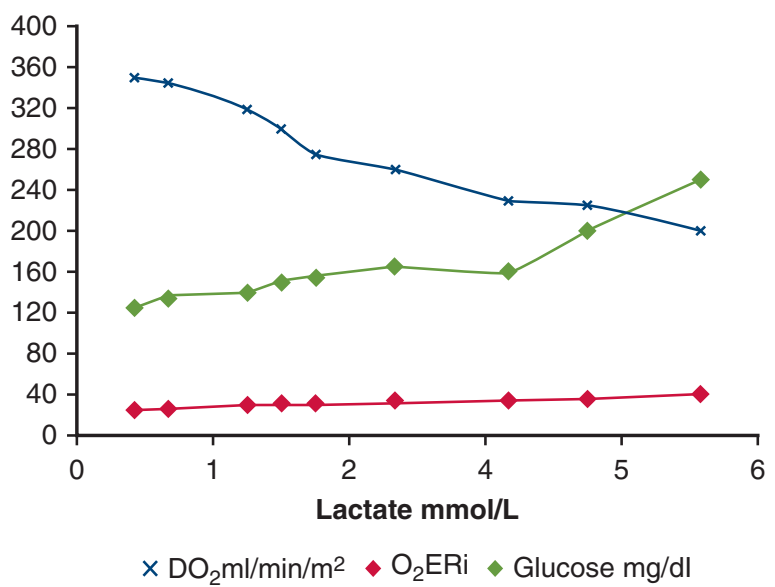

FIGURE 2. Lactate and glucose trend according to the distribution of target indexed oxygen delivery $\left(D O_{2 i}\right)$ level and indexed oxygen extraction ratio $\left(\mathrm{O}_{2} E R_{i}\right)$ during cardiopulmonary bypass. 
TABLE 5. Subgroup analysis for peak blood lactate and lowest cardiac index $(\mathrm{CI})$ in relation to mixed venous oxygen saturation $\left(\mathrm{SvO}_{2}\right)$ on cardiopulmonary bypass for group $B(n=250)$

\begin{tabular}{lcccc}
\hline \multicolumn{1}{c}{ Variable } & No HL or HG & HL alone & HG alone & HL and HG \\
\hline No. of patients & 187 & 10 & 21 & 32 \\
Peak blood lactate $(\mathrm{mmol} / \mathrm{L})$ & $1.39 \pm 0.69$ & $3.48 \pm 0.38$ & $1.79 \pm 0.55$ & $5.31 \pm 3.83$ \\
Lowest $\mathrm{CI}\left(\mathrm{L} / \mathrm{min} / \mathrm{m}^{2}\right)$ & $2.4 \pm 0.2$ & $2.4 \pm 0.1$ & $2.4 \pm 0.1$ & $1.8 \pm 0.4$ \\
Lowest $\mathrm{SvO}_{2}(\%)$ & $80 \pm 3$ & $73 \pm 1$ & $72 \pm 1$ & $55 \pm 12$ \\
\hline
\end{tabular}

Values are presented as mean \pm standard deviation. $\mathrm{HL}$, Hyperlactatemia; $\mathrm{HG}$, hyperglycemia; $\mathrm{CI}$, cardiac index; $\mathrm{SvO}_{2}$, mixed venous oxygen saturation.

Univariate association with peak blood lactate was tested with a correlation matrix. Factors significantly $(P<.05)$ associated with peak blood lactate at this preliminary step were entered into a stepwise forward multivariable linear regression analysis, with adequate corrections to avoid multicollinearity within the model. The multivariable approach was applied to assess the independent association between the variables tested and peak blood lactate. Subsequently, the population was explored in terms of $\mathrm{HL}(>3 \mathrm{mmol} / \mathrm{L})$ incidence. Normally distributed continuous variables are expressed as means \pm standard deviation, and categorical variables as frequencies and percentages. $\mathrm{DO}_{2 \mathrm{i}}$ in relation to target $\mathrm{O}_{2} \mathrm{ER}_{\mathrm{i}}$ vs CI in relation to $\mathrm{SvO}_{2}$ during CPB were tested for association with peak lactate and peak glucose blood. Intraoperative variables were tested for predictive ability of HL by using a receiver operating characteristic analysis. Postoperative outcome was firstly analyzed in the population with or without HL during CPB using a univariate approach (Student $t$ test for unpaired data or relative risk analysis) and was subsequently corrected for other covariates.

\section{RESULTS}

Demographic, preoperative, and operative details of the patient population are shown in Tables 1 and 2. Eight preand intraoperative factors were found to be significantly associated with peak blood lactate level during CPB at univariate analysis (Table 3): age, isolated coronary operation, lowest pump flow, lowest temperature, $\mathrm{Hct}$, and $\mathrm{DO}_{2 \mathrm{i}}$ were negatively correlated with peak blood lactate value during $\mathrm{CPB}$, whereas $\mathrm{CPB}$ duration and peak blood glucose were positively correlated with peak blood lactate value during $\mathrm{CPB}$. The same intraoperative factors were tested for

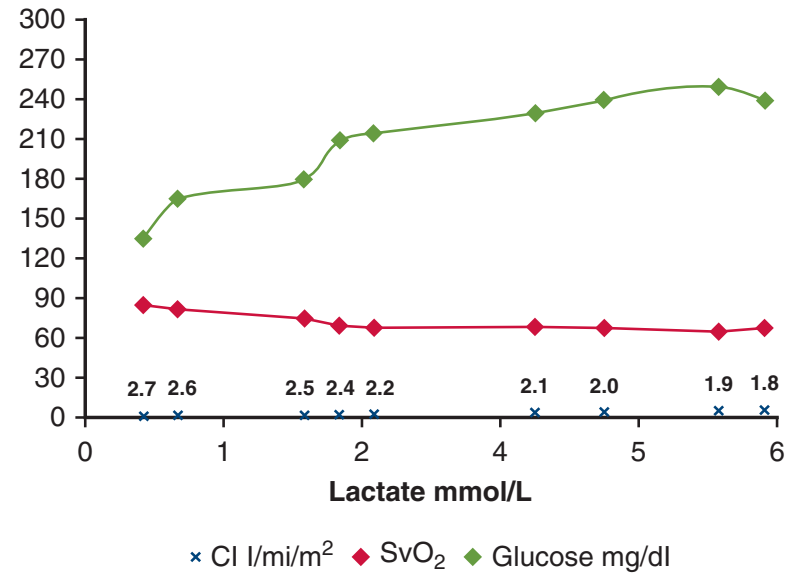

FIGURE 3. Lactate and glucose trend according to the distribution of cardiac index $(\mathrm{CI})$ level and mixed venous oxygen saturation $\left(\mathrm{SvO}_{2}\right)$ during cardiopulmonary bypass. predictivity of $\mathrm{HL}$ with receiver operating characteristic analysis (Figure 1). The area under the curve was significant for all factors. We therefore decided to explore the adequate cutoff values for target $\mathrm{DO}_{2 \mathrm{i}}$ in relation to $\mathrm{O}_{2} \mathrm{ER}_{\mathrm{i}}$ versus CI in relation to $\mathrm{SvO}_{2}$ ratio during $\mathrm{CPB}$ as possible predictors of HL. A cutoff of $\mathrm{DO}_{2 \mathrm{i}}<270 \mathrm{~mL} / \mathrm{min} / \mathrm{m}^{2}$ in relation to $\mathrm{O}_{2} \mathrm{ER}_{\mathrm{i}}>35 \%$ during $\mathrm{CPB}$ in group $\mathrm{A}$ (Table 4 and Figure 2) and a cutoff of $\mathrm{CI}<2.4 \mathrm{~L} / \mathrm{min} / \mathrm{m}^{2}$ in relation to $\mathrm{SvO}_{2}<65 \%$ in group B (Table 5 and Figure 3) were found to have a positive predictive value of $80 \%$ (sensitivity $73 \%$, specificity $76 \%$ ) and $75 \%$ (sensitivity $68 \%$, specificity $67 \%$ ), respectively (Figure 4). A cutoff of $155 \mathrm{mg} / \mathrm{dL}$ for peak blood on CPB showed a positive predictive value of $85 \%$ (sensitivity $84 \%$, specificity $83 \%$ ) (Table 6). A cutoff of $\mathrm{DO}_{2 \mathrm{i}}>290 \mathrm{~mL} / \mathrm{min} / \mathrm{m}^{2}$ in relation to $\mathrm{O}_{2} \mathrm{ER}_{\mathrm{i}} 24 \%$ during $\mathrm{CPB}$ in group A (Figure 2) and a cutoff of CI $>2.4 \mathrm{~L} / \mathrm{min} / \mathrm{m}^{2}$ in relation to $\mathrm{SvO}_{2}>75 \%$ during $\mathrm{CPB}$ in group $\mathrm{B}$ (Figure 3) were found to have a negative predictive value of $78 \%$ (sensitivity $69 \%$, specificity $75 \%$ ) and $62 \%$ (sensitivity $49 \%$, specificity $59 \%$ ), respectively (Figure 4 ). A cutoff of $128 \mathrm{mg} / \mathrm{dL}$ for peak blood glucose on CPB showed a negative predictive value of $74 \%$ (sensitivity $79 \%$, specificity $80 \%$ ) (Table 7$)$. HL ( $>3 \mathrm{mmol} / \mathrm{L})$ was detected in $15(6 \%)$ patients of group $\mathrm{A}$ and in $42(16.8 \%)$ patients of group B $(P=.001)$; hyperglycemia $(>160 \mathrm{mg} / \mathrm{dL})$ was found in $23(9.2 \%)$ patients of group $\mathrm{A}$ and in 53 $(21.2 \%)$ patients of group B $(P=.001)$ (Table 8$)$. Patients without HL or hyperglycemia had significantly lower values of peak blood lactate; patients with both HL and hyperglycemia had significantly higher peak blood lactate values than patients with only HL or hyperglycemia. Only patients with associated HL and hyperglycemia had significantly lower values of $\mathrm{DO}_{2 \mathrm{i}}$ with higher value of $\mathrm{O}_{2} \mathrm{ER}_{\mathrm{i}}$ for group $\mathrm{A}$ and lower CI with low $\mathrm{SvO}_{2}$ for group $\mathrm{B}$ on CPB. Group A patients with higher values of $\mathrm{DO}_{2 \mathrm{i}}$ and $\mathrm{O}_{2} \mathrm{ER}_{\mathrm{i}}$ showed a lower incidence of $\mathrm{HL}$ and hyperglycemia, which was $14.4 \%$ less than in group B patients for $\mathrm{CI}$ and $\mathrm{SvO}_{2}$ target. Patients with HL during CPB had a significant increase in serum creatinine value, ${ }^{13}$ higher rate of prolonged mechanical ventilation time and ICU stay (Table 9 and Figure 5). Patients with hyperglycemia not associated with HL were separately investigated for the outcome variables. No significant differences in terms of morbidity or mortality were detected in association with this isolated condition. 


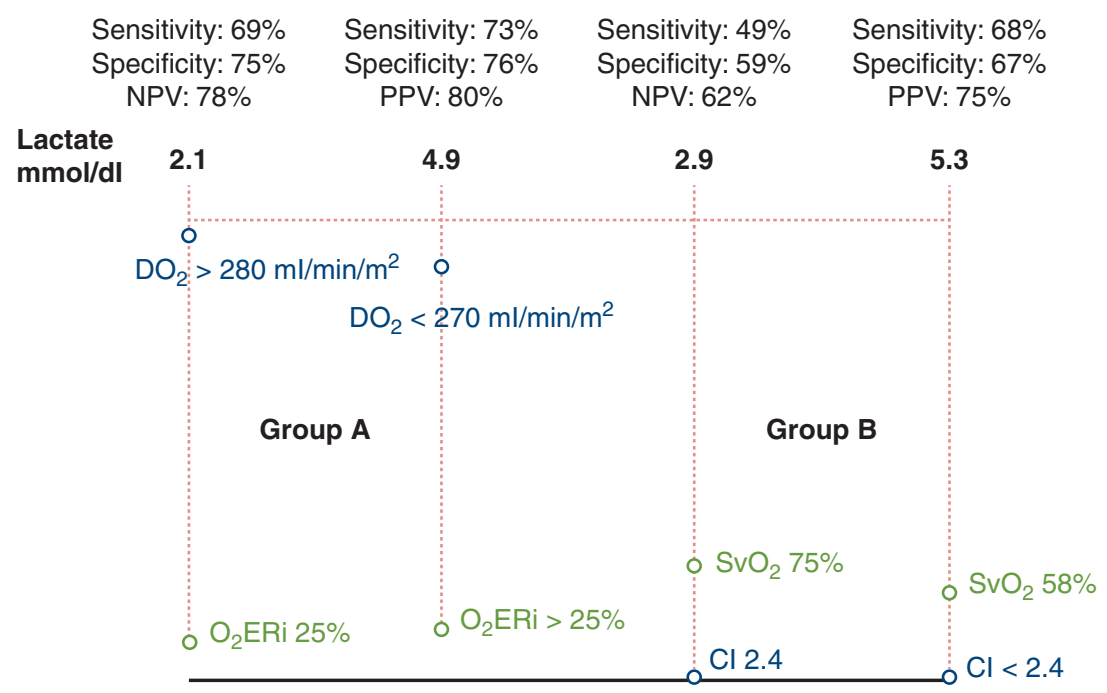

FIGURE 4. Negative predictive value $(N P V)$ and positive predictive value $(P P V)$ of hyperlactatemia. The receiver operating characteristic curve analysis shows that oxygen delivery $\left(D O_{2}\right)>280 \mathrm{~mL} / \mathrm{min} / \mathrm{m}^{2}$ in relation to indexed oxygen extraction ratio $\left(\mathrm{O}_{2} E R_{i}\right) 25 \%$ is more specific and sensitive than the calculated cardiac index $(C I)$, and is 16 times higher as a predictive value for values $<3 \mathrm{mmol} / \mathrm{dL}$ lactates. $\mathrm{SvO}_{2}$, Mixed venous oxygen saturation.

\section{DISCUSSION}

In this analysis we tried to analyze the correlation of lactates and glycemia with the target managed in relation to the oxygen consumption variables, in a different way than in the previous studies, strengthening their conclusions. ${ }^{1-3,9,10}$

Our analysis demonstrates that the management of $\mathrm{DO}_{2 \mathrm{i}}$ in relation to $\mathrm{O}_{2} \mathrm{ER}_{\mathrm{i}}$ was $16 \%$ more specific in terms of negative predictive value for $\mathrm{HL}$ during $\mathrm{CPB}$ compared with the use of $\mathrm{CI}$ in relation to $\mathrm{SvO}_{2}$. The group managed with $\mathrm{DO}_{2}$ and $\mathrm{O}_{2} \mathrm{ER}_{\mathrm{i}}$ reported a significant reduction in the incidence of intraoperative lactate peak, correlated with postoperative reduction of serum creatinine value, mechanical ventilation time, and ICU stay, compared with group managed with $\mathrm{CI}$ and $\mathrm{SvO}_{2}$.

The link between HL and hyperglycemia through the mechanism explained above was confirmed by Revelly and colleagues ${ }^{16}$ in an elegant study dealing with cardiogenic or septic shock. The role of adrenergic agonists in this setting is well defined: in cardiogenic shock, they are both endogenous or administered for cardiovascular therapy; in our model, they are endogenous in the majority of patients. None received epinephrine during $\mathrm{CPB}$, and few received norepinephrine; however, unlike epinephrine, norepinephrine usually does not increase glucose production or induce an increase in plasma lactate concentration. $^{6,17}$ The 2 mechanisms leading to $\mathrm{HL}$ in various clinical conditions are therefore anaerobic metabolism due to a poor $\mathrm{DO}_{2}$ and excess lactate production due to glucose failing to enter the oxidative pathway and being degraded to lactate by the glycolytic pathway. ${ }^{17}$ These mechanisms, if independently considered, lead to different acid-base balance conditions, the former being accompanied by metabolic acidosis and the latter not necessarily so. However, in the clinical conditions of this observational study, the acid-base balance is constantly maintained at a normal $\mathrm{pH}$ value by bicarbonate corrections applied by the perfusionist whenever the base excess starts decreasing. Therefore, we are unable to identify differences in HL related to different values of peak blood lactate. However, the evidence that only 4 patients demonstrated HL without hyperglycemia and that only patients with an HLhyperglycemia syndrome had a significantly lower value of $\mathrm{DO}_{2}$ seems to confirm that, in our specific clinical environment, $\mathrm{HL}$ and hyperglycemia are linked by the causative

TABLE 6. Receiver operating characteristic analysis for the 5 intraoperative positive predictive value (PPV) of hyperlactatemia

\begin{tabular}{lccccccc}
\hline \multicolumn{1}{c}{ Factor } & AUC & 95\% confidence interval & $\boldsymbol{P}$ value & Cutoff value & Sensitivity, \% & Specificity, \% & PPV, \% \\
\hline Lowest $\mathrm{DO}_{2 \mathrm{i}}$ on $\mathrm{CPB}$ & 0.71 & $0.58-0.81$ & .001 & $180 \mathrm{~mL} / \mathrm{min} / \mathrm{m}^{2}$ & 73 & 74 & 75 \\
High $\mathrm{O}_{2} \mathrm{ER}_{\mathrm{i}}$ on CPB & 0.77 & $0.73-0.85$ & .001 & $40 \%$ & 73 & 76 \\
Peak blood glucose on CPB & 0.92 & $0.82-0.97$ & .001 & $160 \mathrm{mg} / \mathrm{dL}$ & 81 & 80 & 85 \\
Low CI on CPB & 0.67 & $0.62-0.80$ & .009 & $1.8 \mathrm{~L} / \mathrm{min} / \mathrm{m}^{2}$ & 65 & 69 \\
Low $\mathrm{SvO}_{2}$ on CPB & 0.65 & $0.60-0.78$ & .007 & $55 \%$ & 68 & 67 \\
\hline
\end{tabular}

$A U C$, Area under the curve; $P P V$, positive predictive value; $D O_{2 i}$, indexed oxygen delivery; $C P B$, cardiopulmonary bypass; $O_{2} E R_{i}$, indexed oxygen extraction ratio; $C I$, cardiac index; $\mathrm{SvO}_{2}$, mixed venous oxygen saturation. 
TABLE 7. Receiver operating characteristic analysis for the 5 intraoperative negative predictive value (NPV) of hyperlactatemia

\begin{tabular}{lccccccc}
\multicolumn{1}{c}{ Factor } & AUC & $\mathbf{9 5} \%$ confidence interval & $\boldsymbol{P}$ value & Cutoff value & Sensitivity, \% & Specificity, \% & NPV, \% \\
\hline High $\mathrm{DO}_{2 \mathrm{i}}$ on $\mathrm{CPB}$ & 0.75 & $0.70-0.83$ & .001 & $299 \mathrm{~mL} / \mathrm{min} / \mathrm{m}^{2}$ & 73 & 74 \\
Low $\mathrm{O}_{2} \mathrm{ER}_{\mathrm{i}}$ on CPB & 0.79 & $0.73-0.85$ & .001 & $24 \%$ & 73 & 76 \\
Low blood glucose on CPB & 0.89 & $0.82-0.93$ & .001 & $128 \mathrm{mg} / \mathrm{dL}$ & 79 & 79 \\
High CI on CPB & 0.68 & $0.65-0.79$ & .039 & $2.4 \mathrm{~L} / \mathrm{min} / \mathrm{m}^{2}$ & 64 & 80 \\
High $\mathrm{SvO}_{2}$ on CPB & 0.63 & $0.60-0.78$ & .035 & $85 \%$ & 62 & 69 \\
\hline
\end{tabular}

$\overline{A U C}$, Area under the curve; $\mathrm{NPV}$, negative predictive value; $\mathrm{DO}_{2 i}$, indexed oxygen delivery; $\mathrm{CPB}$, cardiopulmonary bypass; $\mathrm{O}_{2} E R_{i}$, indexed oxygen extraction ratio; $\mathrm{CI}$, cardiac index; $\mathrm{SvO}_{2}$, mixed venous oxygen saturation.

factor of a poor $\mathrm{DO}_{2}$, leading on 1 hand to lactate production through the anaerobic pathway and on the other hand to a vicious cycle of lactate production due to poor ability to use glucose through the aerobic pathway. ${ }^{2,5,10}$ Reduced oxygen content in cases of acute anemia is usually compensated by reduced blood viscosity with increased blood flow in the microcirculation and by a compensatory increase in cardiac output. ${ }^{12}$ This last mechanism may be impaired during CPB, where pump flow is usually adjusted on the basis of the patient's body surface area and temperature, not the $\mathrm{Hb}$ value. On the basis of our data, the main rationale for explaining $\mathrm{HL}$ during $\mathrm{CPB}$ is a $\mathrm{DO}_{2}$ inadequate to guarantee the needed oxygen consumption of the patient.

In the present study, we investigated the role of potentially modifiable factors related to CPB surgery in determining postoperative $\mathrm{HL}$ and hyperglycemia. ${ }^{11}$ Our results demonstrate, in a relatively large series of patients treated at different sites, that a $\mathrm{DO}_{2 \mathrm{i}}<270 \mathrm{~mL} / \mathrm{min} / \mathrm{m}^{2}$ with $\mathrm{O}_{2} \mathrm{ER}_{\mathrm{i}}>35 \%$ and low $\mathrm{CI}\left(<2.4 \mathrm{~L} / \mathrm{min} / \mathrm{m}^{2}\right)$ with $\mathrm{SvO}_{2}<65 \%$ during CPB are associated with $\mathrm{HL}$ and hyperglycemia and $\mathrm{DO}_{2 \mathrm{i}}>290 \mathrm{~mL} / \mathrm{min} / \mathrm{m}^{2}$ with $\mathrm{O}_{2} \mathrm{ER}_{\mathrm{i}}<25 \%$ and $\mathrm{CI}>2.4 \mathrm{~L} / \mathrm{min} / \mathrm{m}^{2}$ with $\mathrm{SvO}_{2}>75 \%$ during $\mathrm{CPB}$ are associated with a low incidence of HL and hyperglycemia. Various preoperative factors or comorbidities may create the right environment for HL during $\mathrm{CPB}$. Age, female sex, congestive heart failure, low left ventricular ejection fraction, hypertension, atherosclerosis, diabetes, preoperative $\mathrm{Hb}$ value, redo or complex surgery, and emergency procedures were found to be risk factors for HL by Demers and colleagues, ${ }^{1}$ who reported an HL incidence of $18 \%$. Some

TABLE 8. Incidence of hyperlactatemia (HL) and hyperglycemia (HG) in the study population

\begin{tabular}{lccc}
\hline Variable & Group A & Group B & $\boldsymbol{P}$ value \\
\hline No HL-HG & 223 & 187 & .035 \\
HL alone & 4 & 10 & .041 \\
HG alone & 12 & 21 & .029 \\
HL-HG & 11 & 32 & .032 \\
Total HG & 23 & 53 & .001 \\
Total HL & 15 & 42 & .001 \\
\hline
\end{tabular}

$H L$, Hyperlactatemia; $H G$, hyperglycemia. of these factors were confirmed in our study, and other new factors were identified; however, our study population had a significantly shorter CPB duration and a lower degree of hemodilution during CPB. Given that both these factors seem to favor the onset of HL, the lower HL rate in our population is reasonably explained. The role of CPB duration in the determination of HL during CPB has been highlighted by other authors.

Some study limitations should be acknowledged. First, the design of this analysis compares 2 different extracorporeal circulation management methods. In relation to the available literature, the values taken of $75 \%$ for $\mathrm{SvO}_{2}$ and $25 \%$ for $\mathrm{O}_{2} \mathrm{ER}_{\mathrm{i}}$ are not directly comparable because the roller pump used in group B does not correlate the calculated heart rate with the measured heart rate. Second, several patients had peripheral cannulation for CPB, which does not allow us to make a comparison between peripheral versus central cannulation. Moreover, during conventional management; we believed it appropriate not to use hypothermia because the calculated data that we were monitoring corresponded to the set objectives of $2.4 \mathrm{~L} / \mathrm{min}$ flow; this nonmodification of management is intrinsically part of the retrospective nature of the study. Finally, the study focused on CPB with the use of a roller pump and does not consider the centrifuge, but it is also necessary to consider that, with its limitations, the roller pump is predominant in the daily use of cardiac surgery centers. ${ }^{18}$ The pump flow is delivered with a roller pump, often the flow management is calculated and not measured with an ultrasonic flowmeter, ${ }^{19}$ this often

TABLE 9. Hyperlactatemia (HL) during cardiopulmonary bypass and postoperative outcome

\begin{tabular}{|c|c|c|c|c|}
\hline \multirow[b]{2}{*}{ Variable } & \multicolumn{2}{|c|}{ Group A $(n=250)$} & \multicolumn{2}{|c|}{ Group B $(n=250)$} \\
\hline & $\begin{array}{c}\text { No HL } \\
(\mathrm{n}=235 ; \\
94 \%)\end{array}$ & $\begin{array}{c}\text { HL } \\
(n=15 ; \\
6 \%)\end{array}$ & $\begin{array}{c}\text { No HL } \\
(n=208 ; \\
83.2 \%)\end{array}$ & $\begin{array}{c}\text { HL } \\
(\mathrm{n}=42 ; \\
16.8 \%)\end{array}$ \\
\hline $\begin{array}{l}\text { Peak serum } \\
\text { creatinine } \\
(\mathrm{mg} / \mathrm{dL})\end{array}$ & $1.1 \pm 1.0$ & $1.9 \pm 1.5$ & $1.2 \pm 1.1$ & $1.9 \pm 1.5$ \\
\hline MV time (h) & $20.6 \pm 45$ & $54 \pm 49$ & $23.6 \pm 55$ & $54 \pm 49$ \\
\hline ICU stay (d) & $2.8 \pm 2.1$ & $5.7 \pm 4.9$ & $3.1 \pm 2.1$ & $6.4 \pm 3.9$ \\
\hline
\end{tabular}

Values are presented as mean \pm standard deviation. $H L$, Hyperlactatemia; $M V$, mechanical ventilation; $I C U$, intensive care unit. 


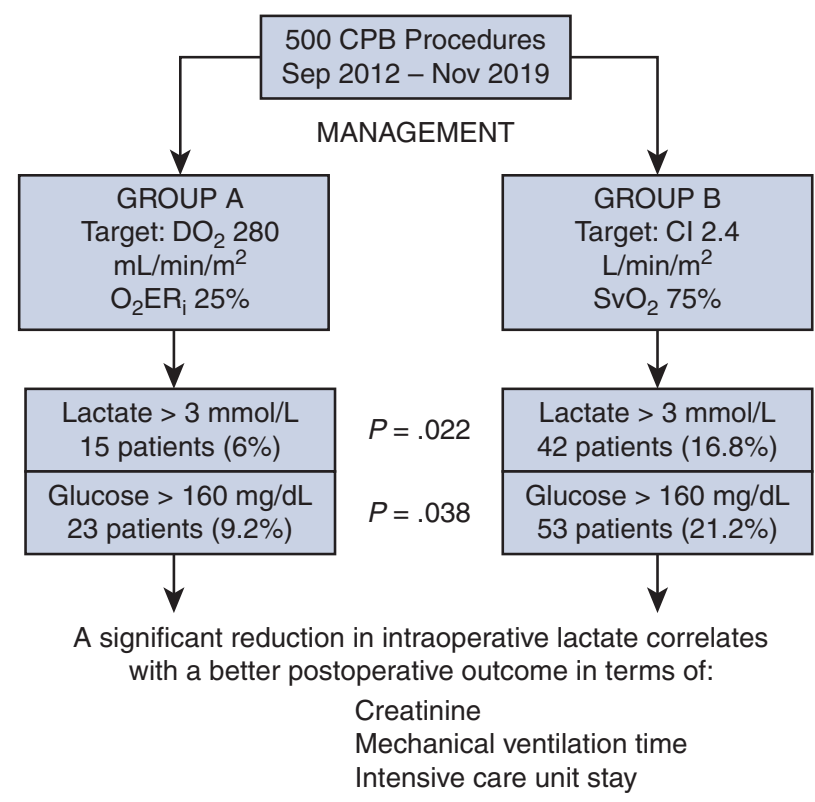

FIGURE 5. Data on 500 cardiopulmonary bypass $(C P B)$ procedures were retrospectively collected, the management of indexed oxygen delivery $\left(D O_{2 i}\right)$ in relation to indexed oxygen extraction ratio $\left(\mathrm{O}_{2} E R_{i}\right)$ follow the $\mathrm{CPB}$ was more specific in terms of negative predictive value for hyperlactatemia compared with the use of cardiac index $(C I)$ in relation to mixed venous oxygen saturation $\left(\mathrm{SvO}_{2}\right)$. That management can correlate with postoperative better outcome especially in terms of serum creatinine, mechanical ventilation time and intensive care unit stay.

involves an overestimation (eg, due to occlusion of the rotor, technique with which the occlusion is made, vacuum-assisted venous drainage use, hypothermia, viscosity, positioning of the cannula, or material of the pump). Our center used a roller pump with a half silicone tube, and an occlusion of $1 \mathrm{~cm}^{2} / \mathrm{min}$ on a three-eighths meter high column. For reasons described above, a $0.3 \pm 0.2$ index discrepancy occurred with ultrasound monitoring that allowed us to evaluate lower cardiac indexes that we could not have evaluated without this gap.

\section{CONCLUSIONS}

This retrospective observational study showed that management of $\mathrm{DO}_{2 \mathrm{i}}$ in relation to $\mathrm{O}_{2} \mathrm{ER}_{\mathrm{i}}$ was $16 \%$ more specific in terms of negative predictive value for HL during $\mathrm{CPB}$ compared with the use of $\mathrm{CI}$ in relation to $\mathrm{SvO}_{2}$. Group A patients showed a significant reduction in the incidence of intraoperative lactate peak, correlated with postoperative reduction of serum creatinine value, mechanical ventilation time, and ICU stay, compared with group B patients.

\section{Conflict of Interest Statement}

The authors reported no conflicts of interest.
The Journal policy requires editors and reviewers to disclose conflicts of interest and to decline handling or reviewing manuscripts for which they may have a conflict of interest. The editors and reviewers of this article have no conflicts of interest.

\section{References}

1. Demers P, Elkouri S, Martineau R, Couturier A, Cartier R. Outcome with high blood lactate levels during cardiopulmonary bypass in adult cardiac surgery. Ann Thorac Surg. 2000;70:2082-6.

2. Ranucci M, Isgro G, Romitti F, Mele S, Biagioli B, Giomarelli P. Anaerobic metabolism during cardiopulmonary bypass: the predictive value of carbon dioxide derived parameters. Ann Thorac Surg. 2006;81:2189-95.

3. Maillet JM, Le Besnerais P, Cantoni M, Nataf P, Ruffenach A, Lessana A, et al. Frequency, risk factors, and outcome of hyperlactatemia after cardiac surgery. Chest. 2003;123:1361-6.

4. Landow L. Splanchnic lactate production in cardiac surgery patients. Crit Care Med. 1993;21(2 suppl):S84-91.

5. Boldt J, Piper S, Murray P, Lehmann A. Case 2-1999. Severe lactic acidosis after cardiac surgery: sign of perfusion deficits. J Cardiothorac Vasc Anesth. 1999;13:220-4.

6. Totaro R, Raper RF. Epinephrine induced lactic acidosis following cardiopulmonary bypass. Crit Care Med. 1997;25:1693-9.

7. Weil MH, Afifi AA. Experimental and clinical studies on lactate and pyruvate as indicators of the severity of acute circulatory failure (shock). Circulation. 1970; 41:989-1001.

8. Rashkin MC, Bosken C, Baughman RP. Oxygen delivery in critically ill patients. Relationship to blood lactate and survival. Chest. 1985;87:580-4.

9. Takala J, Uusaro A, Parviainen I, Ruokonen E. Lactate metabolism and regional lactate exchange after cardiac surgery. New Horiz. 1996;4:483-92.

10. Ranucci M, De Toffol B, Isgro G, Romitti F, Conti D, Vicentini M. Hyperlactatemia during cardiopulmonary bypass: determinants and impact on postoperative outcome. Crit Care. 2006;10:R167.

11. Raper RF, Cameron G, Walker D, Bovey CJ. Type B lactic acidosis following cardiopulmonary bypass. Crit Care Med. 1997;25:46-51.

12. Habib RH, Zacharias A, Schwann TA, Riordan CJ, Durham SJ, Shah A. Adverse effects of low hematocrit during cardiopulmonary bypass in the adult: should current practice be changed? J Thorac Cardiovasc Surg. 2003;125:1438-50.

13. Mehta RL, Kellum JA, Shah SV, Molitoris BA, Ronco C, Warnock DG, et al Acute Kidney Injury Network: a report of an initiative to improve outcomes in acute kidney injury. Crit Care. 2007;11:R31.

14. Mehta RH, Grab JD, O'Brien SM, Bridges CR, Gammie JS, Haan CK, et al. Bedside tool for predicting the risk of postoperative dialysis in patients undergoing cardiac surgery. Circulation. 2006;114:2208-16.

15. de Somer F, Mulholland JW, Bryan MR, Aloisio T, Van Nooten GJ, Ranucci M $\mathrm{O}_{2}$ delivery and $\mathrm{CO}_{2}$ production during cardiopulmonary bypass as determinants of acute kidney injury: time for a goal-directed perfusion management? Crit Care. 2011;15:R19.

16. Revelly JP, Tappy L, Martinez A, Bollmann M, Cayeux MC, Berger MM, et al Lactate and glucose metabolism in severe sepsis and cardiogenic shock. Crit Care Med. 2005;33:2235-40.

17. Ensinger H, Geisser W, Brinkmann A, Wachter U, Vogt J, Radermacher P, et al. Metabolic effects of norepinephrine and dobutamine in healthy volunteers. Shock. 2002;18:495-500.

18. Baker RA, Willcox TW. Australian and New Zealand perfusion survey: equipment and monitoring. J Extra Corpor Technol. 2006;38:220-9.

19. Puis L, Milojevic M, Boer C, De Somer FMJJ, Gudbjartsson T, van den Goor J, et al. 2019 EACTS/EACTA/EBCP guidelines on cardiopulmonary bypass in adult cardiac surgery. Interact Cardiovasc Thorac Surg. 2020;30: 161-202.

Key Words: hyperlactatemia, oxygen delivery, cardiac index, cardiopulmonary bypass 